\title{
PENGEIMBANGAN MEDIA PEMBELAJARAN MENGGUNAKKAN SOFTWARE MINDJET MINDMANAGER PADA AKUNTANSI DASAR SIMK KELAS X AKL
}

\author{
Elit Aminatus Saadah ${ }^{1}$, Agung Listiadi ${ }^{2}$ \\ Universitas Negeri Surabaya
}

\begin{abstract}
The purpose of this study is to 1) determine the process of developing mind mapping media using mindjet mindmanager 2017 software for basic accounting subjects for Vocational High School class X AKL, 2) to be able to determine the feasibility level of mind mapping media made by researchers for class $X$ AKL with basic accounting. as a subject, 3) to be able to find out the response to vocational students in class $X A K L$ regarding the mind mapping media developed by researchers. The type in this research is the development with the 4D Thiagarajan model with four stages, namely the first stage of defining, the second stage of planning, the third stage of development and finally the stage of deployment. This development research uses review sheets and expert validation and student response questionnaires as research instruments. The learning media was tested on 20 class X AKL vocational students from SMK Ketintang Surabaya. Mind mapping learning media get criteria of "feasible" with a percentage of $79 \%$ of material experts and criteria of "very feasible" with a percentage of $87 \%$ of media experts. Meanwhile, the student response got the criteria of "very good" with a percentage of $95 \%$. Based on the explanation above, it can be stated that mind mapping media is feasible to be used in learning basic accounting material.
\end{abstract}

Keywords: learning media, mind mapping, mindjet minmanager software, basic accounting

\section{PENDAHULUAN}

Pendidikan adalah komponen yang sangat penting dalam menciptakan negara yang maju melalui pemberdayaan Sumber Daya Manusia yang optimal. ${ }^{1}$ Fungsi diadakannya pendidikan yaitu untuk mengasah kemampuan yang dimiliki siswa dan membentuk sikap siswa agar beriman, mulia, bertaqwa, sehat, kreatif dan mandiri. Pendidikan dapat mencapai tujuannya jika didukung dengan pembelajaran yang efektif. Pengertian dari pembelajaran efektif yaitu metode yang dimanfaatkan untuk membantu siswa agar sampai pada tujuan dalam pembelajaran tersebut, misalnya dengan mengasah potensi diri dan memberikan siswa kemudahan dalam menguasai materi ${ }^{2}$. Di Indonesia ada tiga

${ }^{1}$ Argelina Novi Oktaviana and Guntur Trimulyono, 'Kelayakan Teoritis Media Video Mind Mapping Untuk Melatih Kemampuan Berpikir Kreatif Peserta Didik Kelas X Pada Materi Fungi', BioEdu Berkala Ilmiah Pendidikan Biologi, 7.2 (2018), 187-93 (p. 187).

${ }^{2}$ Arief Davis Bagus Susanto, 'Analisis Perbandingan Hasil Belajar Siswa Pada Penerapan Pembelajaran Melalui Pendekatan Saintifik Dengan Dan Tanpa Berbantuan Mind Mapping Pada Mata Pelajaran Dasar - Dasar Perbankan Kelas X Akuntansi Di SMK Negeri 2 Buduran', Jurnal Pendidikan Akuntansi (JPAK), 6.3 (2018), 226-29 (p. 226). 
macam jenis pendidikan yaitu berisfat formal, non-formal dan informal. Sekolah Menengah Kejuruan adalah contoh dari pendidikan di Indonesia yang bersifat formal dan lebih fokus dalam menyiapkan siswa untuk menjadi tenaga kerja yang telah memiliki bekal dalam pengetahuan, keterampilan, keahlian dan hasil akhirnya siap untuk bekerja ${ }^{3}$. Program keahlian di Sekolah Menengah Kejuruan cukup banyak salah satunya Program Keahlian Akuntansi dan Keuangan Lembaga yang lebih fokus pada keahlian siswa tentang akuntansi.

Akuntansi dan Keuangan Lembaga merupakan contoh dari program keahlian yang ditawarkan pada Sekolah Menengah Kejuruan yang memiliki peminat cukup banyak. 4Menurut Pusat Kurikulum, Balitbang Depdiknas, 2003 proses belajar akuntansi pada Sekolah Menengah Kejuruan bermanfaat mengembangkan keterampilan, pengetahuan, sikap logis, jujur, teliti dan bertanggung jawab terkait kegiatan dalam akuntansi hingga menjadi laporan keuangan dan dapat dianalisis berdasarkan Standar Akuntansi Keuangan.5 Untuk itu sangat penting bagi siswa memahami konsep yang disampaikan oleh pendidik terkait yang merupakan suatu keahlian yang dimiliki siswa pada bagian kognitif terkait daya ingat dan penciptaan agar dapat memecahkan masalah atau mengerjakan soal.

Proses pembelajaran sangatlah penting untuk membantu siswa memahami konsep yang diajarkan. ${ }^{6}$ Suatu tahapan pembelajaran yang memiliki kualitas baik akan membantu siswa dalam mendapatkan pengalaman belajar yang tentunya bermanfaat bagi dirinya dan dapat mengembangkan bakat ataupun minatnya yang nanti akan menjadi bekal untuk menguasai konsep dalam mengikuti pembelajaran selanjutnya. ${ }^{7}$ Media dalam pembelajaran akuntansi berperan penting dalam proses pembelajaran dalam kelas karena menjadi salah satu faktor keberhasilannya. ${ }^{8}$ Di zaman yang semakin maju, banyak teknologi yang dapat digunakkan untuk membantu dalam kegiatan pembuatan media

${ }^{3}$ Eka Fitriana, 'Pengembangan Media E-Modul Berbasis Aplikasi Android Materi Persamaan Dasar Akuntansi Mata Pelajaran Akuntansi Dasar Kelas X Akuntansi Di SMK PGRI 1 Tulungagung', Jurnal Mahasiswa Teknologi Pendidikan, 9.2 (2018).

${ }^{4}$ Hendri Gunawan, 'Pengembangan E-Modul Akuntansi Akuntansi Kompetensi Dasar Mencatat Transaksi Dalam Persamaan Dasar Akuntansi Di Sekolah Menengah Kejuruan', Jurnal Neraca, 4.1 (2020), 84-96 (p. 85) <https://doi.org/10.31851/neraca.v4i1.4311>.

${ }^{5}$ Rani Nur Arifah Fajrina, Supriyono Koes Handayanto, and Arif Hidayat, 'Deskripsi Penguasaan Konsep Siswa Terhadap Materi Fluida Statis Di Tana Paser Kalimantan Timur Kelas XI Tahun Ajaran 2016/2017', Pros.Seminar Pend.IPA Pascarjana UM, 1 (2016), 416-22 (p. 416).

${ }^{6}$ Choiriyati Umi, 'Upaya Meningkatkan Kemampuan Siswa Dalam Penguasaan Materi Pembelajaran Persamaan Dasar Akuntansi Dengan Metode Optimalisasi Pembelajaran Berjenjang Pada Siswa Kelas XII IPS 1 SMAN 1 Pringgasela Semester Ganjil T.P 2017-2018', Journal Ilmiah Rinjani_Universitas Gunung Rinjani, 6.2 (2018), 189-200 (p. 190).

${ }^{7}$ Rizqi Ilyasa Aghni, 'Fungsi Dan Jenis Media Pembelajaran Dalam Pembelajaran Akuntansi', Jurnal Pendidikan Akuntansi Indonesia, 16.1 (2018), 98-107 (p. 107) <https://doi.org/10.21831/jpai.v16i1.20173>.

${ }^{8}$ Wandah Wibawanto, Desain Dan Pemrograman Multimedia Pembelajaran Interaktif, ed. by Dhega Febiharsa, 1st edn (Jember: Penerbit Cerdas Ulet Kreatif, 2017), pp. 8-9 $<$ https://play.google.com/books/reader?id=9pULDgAAQBAJ\&hl=id\&lr=\&printsec=frontcover\&pg=GB S.PR2>. 
pembelajaran dari media teknologi cetak, audio visual, media berbasis komputer dan media dari teknologi gabungan.

${ }^{9}$ Berdasarkan permendikbud 22 Tahun 2020 Tentang Rencana Strategis Kementerian Pendidikan dan Kebudayaan Tahun 2020-2024 terkait permasalahan dan potensi pembangunan pendidikan dan kebudayaan diketahui bahwasanya hasil pembelajaran di Indonesia masih sangat rendah. ${ }^{10}$ Nilai mata pelajaran siswa dipengaruhi oleh faktor internal dan eksternal dari siswa. Faktor internal berasal dari gangguan pada kesehatan, cacat tubuh, perhatian siswa, minat siswa, intelegensi siswa, kematangan dan kesiapan siswa serta motivasi dari siswa. ${ }^{11}$ Sedangkan menurut Majid, 2008 faktor eksternal berasal dari sekolah, keluarga dan masyarakat. ${ }^{12}$ Berdasarkan SE No.4 Tahun 2020 tentang Pelaksanan Kebijakan Pendidikan dalam Masa Darurat Penyebaran CORONAVIRUS DISEASE (COVID-19) sejak Bulan Maret 2020 pembelajaran dilakukan dari rumah atau pembelajaran secara daring. Namun, ditemukan permasalahan dalam pembelajaran daring yaitu para siswa yang mengalami kebosanan dan menurunnya tingkat motivasi belajar pada siswa. Permasalahan ini juga ditemukan di SMK Ketintang Surabaya berdasarkan pada wawancara yang dilakukan dengan guru di SMK Ketintang Surabaya bahwasanya hasil belajar akuntansi dasar pada siswa rata-rata masih rendah saat dilakukannya pembelajaran secara daring ditengah pandemi COVID-19. Hal itu dibuktikan dengan hasil tugas siswa dan hasil ulangan harian siswa. Hasil belajar yang rendah pada siswa menunjukkan bahwa masih belum paham dan belum sepenuhnya siswa dapat menerapkan cara dalam ilmu akuntansi secara baik dan benar pada mata pelajaran akuntansi dasar yang memiliki dampak yang berkelanjutan dalam mengikuti dan memahami materi selanjutnya. Selain itu berdasarkan wawancara dengan siswa di Sekolah Menengah Kejuruan Ketintang Surabaya program keahlian akuntansi dan keuangan lembaga diperoleh informasi jika siswa mengalami masalah terkait motivasi belajarnya karena pembelajaran yang dilakukan secara daring dirasa sangat monoton dan membosankan dengan banyak materi untuk dipahami secara mandiri membuat siswa malas untuk mempelajari mata pelajaran akuntansi dasar dan pada akhirnya siswa kesulitan untuk memahami maupun menyelesaikan soal yang ada. ${ }^{13}$ Pengertian dari motivasi belajar sendiri yaitu dorongan yang berasal dari siswa itu sendiri baik secara internal maupun eksternal pada kegiatan belajar dengan melakukan perubahan pada

\footnotetext{
${ }^{9}$ Indonesia Republik, 'Peraturan Menteri Pendidikan Dan Kebudayaan Republik Indonesia Nomor 22 Tahun 2020 Tentang Rencana Strategis Kementerian Pendidikan Dan Kebudayaan Tahun 2020-2024', Lembaran Negara RI Tahun 2020, 2020.

${ }^{10}$ Siti Nurhasanah and A. Sobandi, 'Minat Belajar Sebagai Determinan Hasil Belajar Siswa', Jurnal Pendidikan Manajemen Perkantoran, 1.1 (2016), 128-35 (p. 130) <https://doi.org/10.17509/jpm.v1i1.3264>.

${ }^{11}$ Nurhasanah and Sobandi, p. 130.

${ }^{12}$ Republik Indonesia, 'SE No. 4 Tahun 2020 Tentang Pelaksanaan Kebijakan Pendidikan Dalam Masa Darurat Penyebaran CoronaVirus Disease (COVID 19)', 2020, 1-3 (p. 1).

${ }^{13}$ Sayu Putri Ningrat, I Made Tegeh, and Made Sumantri, 'Kontribusi Gaya Belajar Dan Motivasi Belajar Terhadap Hasil Belajar Bahasa Indonesia', Journal of Education Technology, 2.4 (2018), 145-52 (p. 147) <https://doi.org/10.23887/jisd.v2i3.16140>.
} 
tingkah laku ataupun dengan beberapa indicator. Siswa yang sedang belajar akuntansi pengantar memerlukan sebuah pemikiran yang logis/kognitif untuk mengaitkan dua sumber informasi/lebih (Tanaka, et all, 2017) ${ }^{14}$. ${ }^{15}$ Berdasarkan Permendikbud Nomor 22 tahun 2016 yang menyatakan bahwa dalam pembelajaran harus memanfatkan kecanggihan pada teknologi agar terciptanya efesiensi dan efektivitas dalam pembelajaran. Oleh karena itu, diperlukan solusi agar pembelajaran daring dengan memanfaatkan teknologi motivasi siswa dapat meningkat.

Mind mapping menjadi salah satu inovasi pembelajaran yang efektif. ${ }^{16}$ Penelitian yang berjudul "Effectiveness of Mind Mapping Tecnique in Information Retrieval Among Medical College Student in Puducherry a Pilot Study" menyatakan bahwasanya mind mapping lebih efektif daripada buku teks. Di era digital ini pembuatan mind mapping lebih mudah dan lebih kreatif karena dibantu dengan software seperti iMindMap, MindManager, MindMeister, MindNote dan FreeMind (Zip, 2011) ${ }^{17}$. Dengan menggunakkan software mindjet mindmanager 2017, tampilan mind mapping akan lebih menarik dengan warna dan bentuk yang cenderung digemari siswa dan software mindjet mindmanager 2017 dapat membantu mind mapping yang dibuat untuk terhubung (hyperlink) dengan software atau file lain seperti microsoft word, excel ataupun powerpoint. ${ }^{18}$ Mindjet Mindmanager 2017 menjadi aplikasi yang lebih cakap dalam pembuatan mind mapping dan dapat dihubungkan dengan software lain seperti Microsoft word dan macromedia flash.

Penelitian terdahulu yang sesuai pada penelitian ini yaitu, penelitian Randi Kusuma Wardani, Amiruddin Kasim, dan Amran Rede (2017) dengan judul "Pengaruh Penggunaan Mind Manager terhadap Motivasi dan Hasil Belajar Siswa Kelas VII SMPN 3 Palu pada Mata Pelajaran Biologi”. Penelitian ini memperlihatkan bahwa dengan menggunakkan mindmanager motivasi meningkat dan hasil belajar siswa pada kelas eksperimen juga tinggi. Penelitian dari Arief Davis Bagus Susanto(2018) dengan judul “Änalisis Perbandingan Hasil Belajar Siswa pada Penerapan Pembelajaran Melalui Pendekatan Saintifik dengan dan Tanpa Berbantuan Mind Mapping pada Mata Pelajaran Dasar-Dasar Perbankan Kelas X Akuntansi di SMK Negeri 2 Buduran” membuktikan

${ }^{14}$ Nur Khabibah and Agus Wahyudin, 'Pengaruh Pemahaman Analisi Transaksi, Persamaan Dasr Akuntansi Dan Konsep Debit Kredit Terhadap Hasil Belajar Jurnal Penyesuaian Dengan Kemampuan Berpikir Deduktif Sebagai Variabel Moderating', Economic Education Analysis Journal, 9.1 (2020), 18299 (p. 184) <https://doi.org/10.15294/eeaj.v9i1.37248>.

${ }^{15}$ Republik Indonesia, Permendikbud Nomor 22 Tahun 2016 (Indonesia, 2016).

${ }^{16}$ Madhanraj Kalyanasundaram and others, 'Effectiveness of Mind Mapping Technique in Information Retrieval among Medical College Students in Puducherry-A Pilot Study', Indian Journal of Community Medicine, 42.1 (2017), 19-23 <https://doi.org/10.4103/0970-0218.199793>.

${ }^{17}$ Wan Noor Hazlina Wan Jusoh Suraya Ahmad, 'IMindMap as An Innovative Tool in Teaching and Learning Accounting: An Exploratory Study', Emerald Insight, 13.1 (2016), 1-13 <https://doi.org/http://dx.doi.org/10.1108/ITSE-05-2015-0012>.

${ }^{18}$ Nurfiah Alfiani Putri, Ajo Dian Yusandika, and Deden Makbuloh, 'Pengembangan Media Pembelajaran Berbasis Mindjet Mindmanager 2017 Pada Pokok Bahasan Usaha Dan Energi', Indonesian Journal of Science and Mathematics Education, 2.1 (2019), 55-63 (p. 61) <https://doi.org/10.24042/ijsme.v2i1.3972>. 
bahwa hasil belajar peserta didik meningkat dengan dengan pendekatan saintifik berbantuan Mind Mapping. Penelitian dari Umi Afifah(2017) dengan judul "Pengembangan Media Pembelajaran Akuntansi dengan Aplikasi Mindjet MindManager pada Materi Jurnal Penyesuaian dan Kertas Kerja Akuntansi Perusahaan Jasa untuk Kelas X Akuntansi SMK Negeri 1 Bojonegoro" menunjukkan bahwasanya media tersebut layak untuk digunakkan.

Berdasarkan pemaparan diatas, maka peneliti hendak melakukan penelitian pengembangan berjudul "pengembangan media pembelajaran berbasis mind mapping menggunakkan software mindjet mindmanager 2017 pada mata pelajaran akuntansi dasar kelas X akuntansi keuangan dan Lembaga SMK Ketintang Surabaya”.

Sedangkan tujuan penelitian pengembangan yang hendak dilakukan oleh peneliti adalah 1) untuk dapat mengetahui langkah-langkah atau proses dan hingga dapat menghasilkan produk media berbasis mind mapping menggunakkan software mindjet mindmanager 2017 pada mata pelajaran akuntansi dasar SMK kelas X AKL , 2) untuk dapat mengetahui tingkat kelayakan pada media mind mapping dengan software mindjet mindmanager 2017 pada akuntansi dasar SMK kelas X AKL, 3) untuk dapat mengetahui respon pada siswa terhadap media mind mapping menggunakkan software mindjet mindmanager 2017 pada akuntansi dasar kelas X AKL di SMK.

\section{METODE PENELITIAN}

Bentuk dari penelitian yang sedang digunakkan yaitu penelitian pengembangan yang merupakan penelitian yang diperuntungkan untuk menciptakan suatu produk dan kemudian diujikan keefektifannya ${ }^{19} .{ }^{20}$ Sedangkan untuk model penelitian yang sedang digunakkan yaitu model 4-D dari Thiagarajan dengan empat tahapan yaitu yang pertama tahapan pendefinisian, kedua tahapan perencanaan, ketiga tahapan pengembangan dan terakhir tahapan penyebaran. Akan tetapi dalam penelitian ini sampai tahapan pengembangan saja karena keterbatasan kemampuan peneliti dalam melakukan penyebaran.

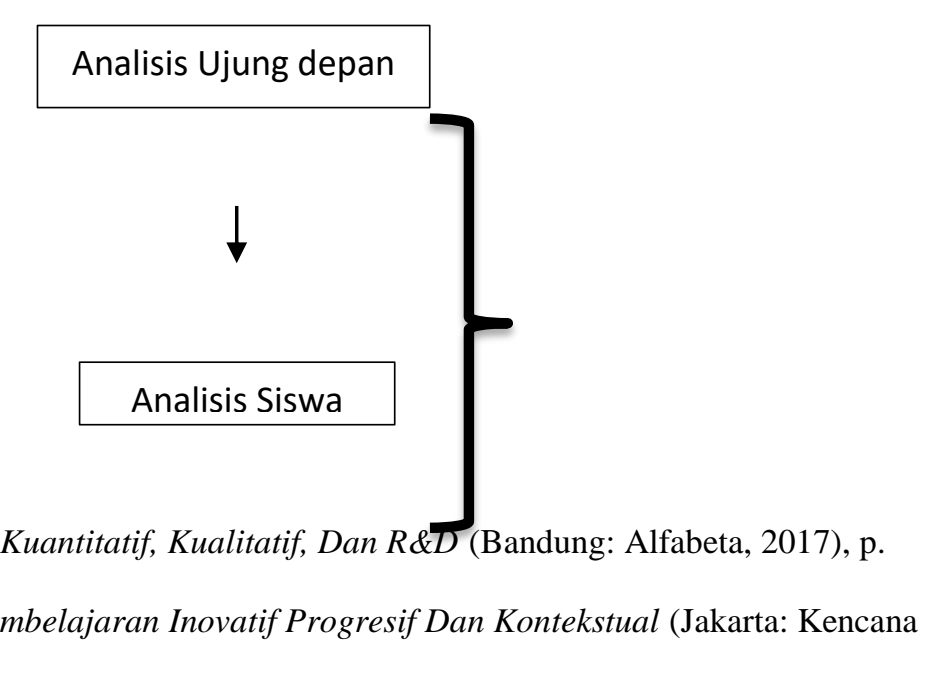

\footnotetext{
${ }^{19}$ Sugiyono, Metode Penelitian Kuantitatif, Kualitatif, Dan R\&D (Bandung: Alfabeta, 2017), p. 297.

20 Trianto, Mendesain Model Pembelajaran Inovatif Progresif Dan Kontekstual (Jakarta: Kencana Prenada Media Group, 2015).
} 


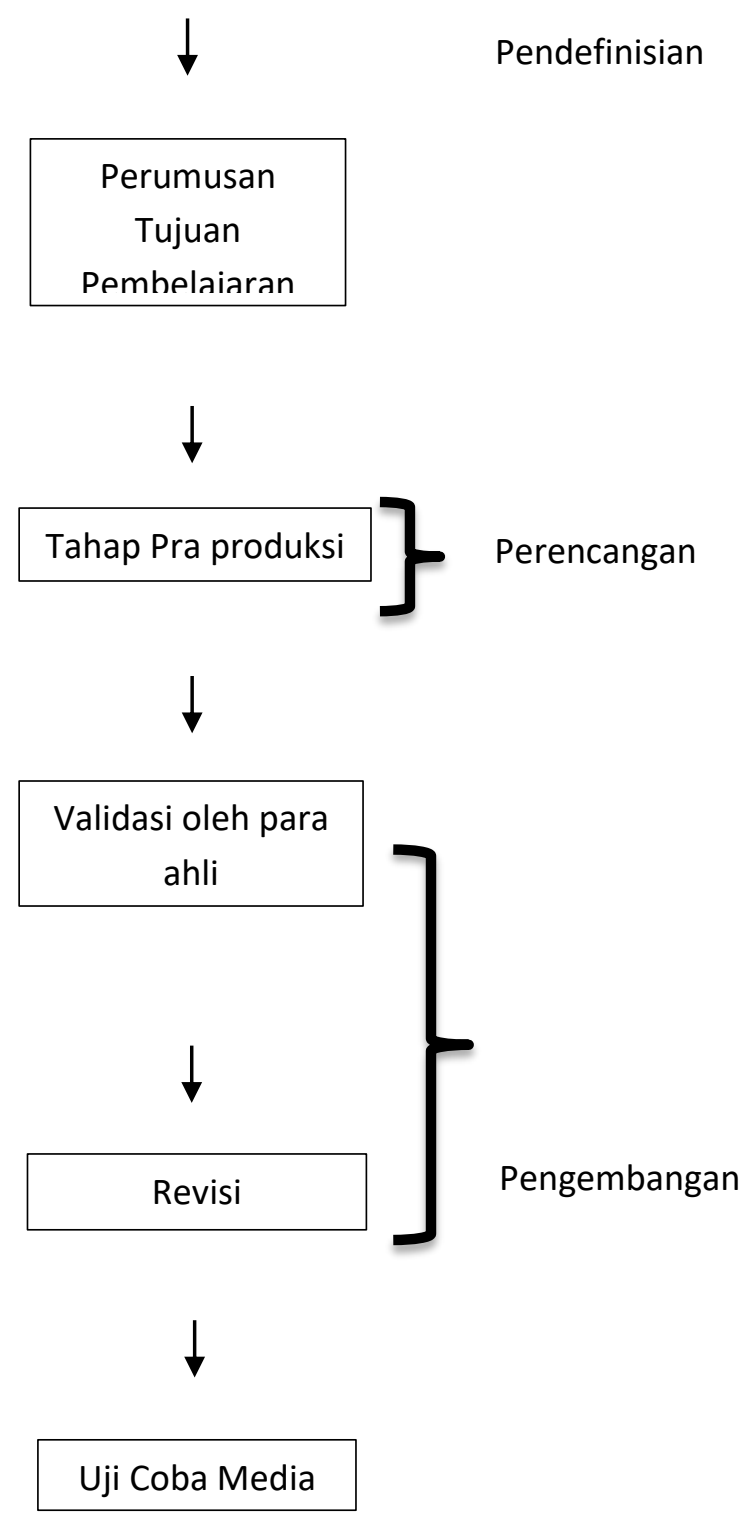

Gambar 1. Model Pengembangan 4D Thiagarajan

Subjek uji coba pada penelitian terdapat satu ahli materi yaitu Guru Mata Pelajaran Akuntansi Dasar SMK Ketintang Surabaya. Sedangkan ahli media berasal dari Dosen Teknologi Pendidikan Fakultas Ilmu Pendidikan Universitas Negeri Surabaya. ${ }^{21}$ Menurut Sadiman untuk uji coba cukup pada kelompok kecil yang dilakukan pada 10 hingga 20 orang. Maka untuk media pembelajaran mind mapping dilakukan uji coba kepada 20 siswa SMK Ketintang Surabaya.

Instrumen dalam mengumpulan data penelitian ini menggunakkan wawancara dan angket. Wawancara dengan jenis tidak terstruktur untuk studi pendahuluan. Angket

${ }^{21}$ Dkk Sadiman, Media Pendidikan: Pengertian, Pengembangan, Dan Pemanfaatannya (Jakarta: PT. Raja Grafindo, 2014). 
terbuka berbentuk angket telaah dari para ahli yaitu ahli materi dan media. Sedangkan angket tertutup berbentuk angket validasi dari para ahli yaitu ahli materi dan media serta angket untuk melihat respon siswa.

Teknik yang digunakkan untuk analisis data dilakukan dengan dua cara yaitu secara deskriptif kualitatif dan deskriptif kuantitatif. Teknik secara deskriptif kualitatif diterapkan pada angket telaah ahli media dan materi sedangkan teknik analisis data secara deskriptif kuantitatif dilakukan pada angket validasi media dan materi yang diolah menggunakkan skala likert bentuk presentase.

Tabel 1. Skor Skala Likert

\begin{tabular}{ll}
\hline Penilaian & $\begin{array}{l}\text { Nilai } \\
\text { Skor }\end{array}$ \\
\hline Sangat baik & 5 \\
\hline Baik & 4 \\
\hline Sedang & 3 \\
\hline Buruk & 2 \\
\hline Sangat buruk & 1 \\
\hline \multicolumn{2}{c}{ Sumber : diadaptasi ${ }^{22}$}
\end{tabular}

Perhitungan untuk memperoleh bentuk presentase menggunakkan rumus.

Presentase $=$ jumlah pada nilai skor total yang didapat/jumlah nilai skor maksimal x $100 \%{ }^{23}$.

Hasil presentase tersebut dapat diartikan dengan ketentuan berikut ini:

Tabel 2. Kriteria Interpretasi Kelayakan

\begin{tabular}{cc}
\hline Presentase (\%) & Kelayakan \\
\hline $0-20$ & Sangat tidak layak \\
\hline $21-40$ & Tidak layak \\
\hline $41-60$ & Cukup layak \\
\hline $61-80$ & Layak \\
\hline $81-100$ & Sangat layak \\
\hline
\end{tabular}

Sumber : diadaptasi ${ }^{24}$

Jika untuk perhitungan pada angket respon siswa mengunakkan skala

Guttman :

15 .

${ }^{22}$ Riduwan, Skala Pengukuran Dan Variabel-Variabel Penelitian (Bandung: Alfabeta, 2016), p.

${ }^{23}$ Riduwan, p. 14.

${ }^{24}$ Riduwan, p. 15. 
Tabel 3. Skala Guttman

\begin{tabular}{ll}
\hline Jawaban & Skor \\
\hline Ya $(\mathrm{Y})$ & 1 \\
\hline Tidak $(\mathrm{T})$ & 0 \\
\hline \multicolumn{2}{l}{ Sumber : diadaptasi ${ }^{25}$}
\end{tabular}

Kemudian hasil dari skala guttman dinayatakan dengan presentase menggunakkan rumus :

Presentase $=$ jumlah pada nilai skor total yang didapat/jumlah nilai skor maksimal $\mathrm{x} 100 \%$.

Presentase dari respon siswa selanjutnya diintersprestasikan sesuai dengan ketentuan berikut ini.

Tabel 4. Interprestasi Kriteria Respon Siswa

\begin{tabular}{cc}
\hline Presentase (\%) & Kelayakan \\
\hline $0-20$ & $\begin{array}{c}\text { Sangat tidak } \\
\text { baik }\end{array}$ \\
\hline $21-40$ & Tidak baik \\
\hline $41-60$ & Cukup baik \\
\hline $61-80$ & Baik \\
\hline $81-100$ & Sangat baik $^{\text {Sumber }: \text { diadaptasi }}{ }^{27}$
\end{tabular}

Sesuai dengan kriteria yang dijelaskan, media pembelajaran dikataakn layak/sangat layak dengan presentase $\geq 61 \%$.

\section{KAJIAN TEORI}

\section{A. Pendidikan}

Pendidikan adalah komponen yang sangat penting dalam menciptakan negara yang maju melalui pemberdayaan Sumber Daya Manusia yang optimal. ${ }^{28}$ Fungsi diadakannya pendidikan yaitu untuk mengasah kemampuan yang dimiliki siswa dan membentuk sikap siswa agar beriman, mulia, bertaqwa, sehat, kreatif dan mandiri. Pendidikan formal di Indonesia untuk menentukan pencapaian dalam tujuan pembelajaran dilihat dari nilai hasil belajar siswa. Contoh dari pendidikan yang bersifat formal di Indonesia yaitu

\footnotetext{
${ }^{25}$ Riduwan, p. 17.

${ }^{26}$ Riduwan, p. 14.

${ }^{27}$ Riduwan, p. 15.

${ }^{28}$ Oktaviana and Trimulyono, p. 187.
} 
Sekolah Menengah kejuruan. ${ }^{29}$ Berdasarkan PP No. 74 pasal 1 ayat 21 Sekolah Menengah Kejuruan merupakan bentuk satuan pendidikan formal yang menyelenggarakan pendidikan kejuruan pada jenjang pendidikan menengah sebagai lanjutan dari Sekolah Menengah Pertama/sederajat. Pada Sekolah Menengah kejuruan mempunyai cukup banyak program keahlian yang disediakan sesuai dengan bakat dan minat siswa.

B. Mata Pelajaran Akuntansi Dasar

Akuntansi dasar adalah salah satu mata pelajaran Program Keahlian Akuntansi dan Keuangan Lembaga yang wajib untuk ditempuh oleh semua siswa. Akuntansi dasar menjadi bekal untuk siswa terkait pembelajaran selanjutnya dalam membuat laporan keuangan. Oleh karena itu sangat penting untuk siswa dapat memahami materi dalam mata pelajaran akuntansi dasar agar dapat mengikuti pembelajaran selanjutnya dengan baik. Dalam akuntansi dasar kelas X Sekolah Menengah Kejuruan terdapat sebelas kompetensi dasar yang harus ditempuh diantaranya yaitu tentang materi peran pada akuntansi dan bagian yang memerlukan informasi akuntansi, materi jenis-jenis profesi akuntansi, materi bentuk badan usaha, materi konsep dasar akuntansi, materi siklus akuntansi, materi persamaan dasar akuntansi, materi transaksi bisnis perusahaan jasa, dagang dan manufaktur, materi jurnal, konsep debet dan kredit, saldo normal, sistematika pencatatan dan bentuk jurnal, materi buku besar, materi jurnal penyesuaian, dan yang terakhir materi neraca lajur hingga jurnal pembalik. ${ }^{30}$

\section{Media Pembelajaran}

${ }^{31}$ Media adalah alat untuk menyampaikan sebuah penjelasan yang mempunyai dampak begitu kuat untuk memotivasi siswa saat kegiatan pembelajaran. Dalam perencanaan pembelajaran harus memperhatikan komponen yang akan digunakkan saat kegiatan pembelajaran. Hal itu karena berdampak pada kemampuan siswa dalam pemahaman pada materi yang diajarkan. Pada era digital ini banyak terobosan yang dilakukan guna memajukan dunia pendidikan salah satunya upaya pemerintah Indonesia dengan melakukan pembaruan kurikulum di Indonesia dengan mengikuti perkembangan teknologi saat ini. Pada saat ini Indonesia menggunakkan kurikulum dimana menekankan keaktifan siswa dan guru sebagai fasilitator yaitu kurikulum 2013 revisi. Peran fasilitator salah satunya menyiapkan media pembelajaran yang berguna utuk menyiapkan informasi atau materi kepada siswa agar pembelajaran dalam kegiatannya dapat berjalan dengan

${ }^{29}$ Republik Indonesia, 'Peraturan Pemerintah Republik Indonesia Nomor 74 Tahun 2008 Tentang Guru', Lembaran Negara RI Tahun 2008, 2008, pasal 1 ayat $221<$ https://www.bertelsmann-

stiftung.de/fileadmin/files/BSt/Publikationen/GrauePublikationen/MT_Globalization_Report_2018.pdf\% 0Ahttp://eprints.lse.ac.uk/43447/1/India_globalisation, society and inequalities(lsero).pdf\%0Ahttps://www.quora.com/What-is-the>.

${ }^{30}$ Toto Sucipto, Akuntansi Dasar Program Keahlian Akuntansi Dan Keuangan, ed. by Gafar Erickasman (Yudhistira, 2017).

${ }^{31}$ Randi Kusuma Wardani, Amiruddin Kasim, and Amran Rede, 'Pengaruh Penggunaan Mind Manager Terhadap Motivasi Dan Hasil Belajar Siswa Kelas VII SMPN 3 Palu Pada Mata Pelajaran Biologi', E-Jip Biol, 5.1 (2017), 26-34 (p. 27). 
lebih efektif dan menumbuhkan motivasi siswa untuk belajar. ${ }^{32}$ Pemilihan sebuah model, metode pembelajaran dan media pada materi yang kurang sesuai dengan karakteristik siswa akan mengakibatkan siswa bosan, sukar dalam memahami materi yang mengakibatkan tidak adanya motivasi pada siswa saat mengikuti pembelajaran. ${ }^{33}$ Dengan media seorang guru dapat dengan mudah menyampaian materi pembelajaran. Oleh karena itu media pembelajaran berperan yang sangat besar untuk mencapai keefektifan dalam tujuan pembelajaran ${ }^{34}$ Dalam pemilihan media pembelajaran menjadi salah satu solusi untuk memaksimalkan tujuan dari pembelajaran dan yang berdampak pada nilai siswa yang meningkat. Dengan memanfaatkan teknologi yang semakin canggih tidak menutup kemungkinan bahwa media pembelajaran akan semakin mudah untuk dikembangkan sesuai dengan karakteristik siswa. Dengan media pembelajaran, motivasi siswa akan meningkat untuk belajar karena motivasi belajar menjadi kekuatan yang menjadi pendorong siswa dalam mengembangkan potensinya yang berasal dari dalam dirinya dan dari luar dirinya untuk mencapai tujuan belajar ${ }^{35}$. Adapun langkah agar motivasi belajar meningkat melalui dalam diri siswa yaitu dengan pembelajaran yang variatif, mengajak siswa lebih aktif dalam pembelajaran, memberikan saran dan motivasi pada siswa, memberikan penghargaan pada siswa yang berhasil menjawab soal ataupun dengan media pembelajaran yang tepat ${ }^{36}$.

D. Mind Mapping

${ }^{37}$ Mind mapping menurut Swadarma, 2013 memiliki peran untuk membantu siswa terkait pandangan sebuah konsep materi pelajaran dan membantu dalam pemahaman suatu keterkaitan dalam hubungan pada konsep-konsep yang ada dalam materi tersebut. Penggunaan mind mapping dapat memberikan kemudahan dalam memahami, menghubungkan konsep satu dengan yang lain serta memudahkan untuk menghafal konsep tersebut (Tungrapa, 2015) ${ }^{38}$. Pada penggunaan mind mapping dengan tampilan yang menarik memberikan pengalaman yang berkesan kepada siswa ${ }^{39}$. Dengan kombinasi warna, kata kunci, dan berbagai bentuk dalam mind mapping memudahkan

${ }^{32}$ Susanto, p. 227.

${ }^{33}$ I Made Yuda Bagaskara, Dewa Nyoman Sudana, and Kadek Yudiana, 'The Positive Impact of SFE Learning Model Assisted with Mind Mapping Media Toward Students' Knowledge Competence in Science', Journal of Education Technology, 4.3 (2020), 317-24

<https://doi.org/10.23887/jet.v4i3.27098>.

${ }^{34}$ Wardani, Kasim, and Rede, p. 28.

${ }^{35}$ Aunurrahman, Belajar Dan Pembelajaran, edisi 1 (Bandung: Alfabeta, 2014).

${ }^{36}$ Hamas Nur Kholid and Amanita Novi Yushita, 'Pengembangan Media Pembelajaran Akuntansi “Accountainment” Pada Kompentensi Dasar Menyiapkan Jurnal Umum Untuk Meningkatkan Motivasi', Kajian Pendidikan Akuntansi Indonesia, 6.8 (2017), 1-25 (p. 2).

${ }^{37}$ Asepma Hygi Prihastuti and Suci Ramadhani, 'Penerapan Metode Pembelajaran Mind Mapping Dan Problem Based Learning Pada Mata Kuliah Akuntansi Keuangan Lanjutan', Eklektik: Jurnal Pendidikan Ekonomi Dan Kewirausahaan, 2.2 (2019), 215-31 (p. 128) <https://doi.org/10.24014/ek1.v2i2.8632>.

${ }^{38}$ Ahmad Muhlisin, 'Reading, Mind Mapping, and Sharing(RMS): Innovation of New Learning Model on Science Lecture to Improve Understanding Concepts', Journal for the Education of Gifted Young Scientists, 7.2 (2019), 323-40 (p. 334) <https://doi.org/10.17478/jegys.570501>.

${ }^{39}$ Ahmad. 
otak untuk menyerap informasi oleh karena itu siswa lebih mudah menghafal konsep dalam materi ${ }^{40}$.

\section{E. Software Mindjet Mindmanager 2017}

Software Mindjet Mindmanager 2017 merupakan salah satu aplikasi yang dapat digunakkan untuk membuat mind mapping dengan meringkas materi dengan penyajian yang dapat disesuaikan dengan selera pembuatnya. Software ini memberikan pilihan terkait penentuan warna, background, symbol, ataupun bentuk dari mind mapping yang akan dibuat. Tidak hanya itu dengan menggunakkan software ini dapat memungkinkan untuk membuat hyperlink terkait kata kunci dalam mind mapping. ${ }^{41}$ Kelebihan pada software ini adalah saat terjadi kesalahan dalam pembuatan mind mapping, akan mudah untuk dibenarkan karena memakai komputer dan banyak menawarkan fitur.

\section{HASIL PENELITIAN DAN PEMBAHASAN}

Media mind mapping dengan menggunakkan software Mindjet Mindmanager pada penelitian ini dikembangkan menggunakkan model model 4-D Thiagarajan dengan empat tahapan yaitu yang pertama tahapan pendefinisian, kedua tahapan perencanaan, ketiga tahapan pengembangan dan terakhir tahapan penyebaran. Akan tetapi dalam penelitian pengembangan ini sampai tahapan pengembangan saja karena keterbatasan kemampuan peneliti dalam melakukan penyebaran.

Tahapan pertama berupa tahap pendefinisian, hal pertama yang dilakukan oleh peneliti yaitu analisis ujung depan berupa studi lapangan terkait permasalahan yang sedang dihadapi baik dari guru maupun siswa pada materi akuntansi dasar agar dalam perencanaan media pembelajaran dapat sesuai dengan karakteristik siswa. Diketahui bahwa siswa dalam proses pembelajaran sering merasa bosan yang berdampak pada hasil belajarnya. Pada tahap ini juga dilakukan analisis siswa agar dapat diketahui karakteristik siswa dan terakhir perumusan tujuan pembelajaran. Pada tahap ini ditemukan bahwa karakteristik siswa yang lebih tertarik pada hal baru, hal yang ringkas namun jelas dan efektif. Untuk umur siswa diketahui antara 14-15 tahun. Kemudian berdasarkan Kurikulum yang digunakkan yaitu K13 revisi dan berdasarkan KIKD, indikator serta silabus peneliti menyesuaikan pembuatan tujuan pembelajaran pada RPP. Karakteristik siswa yang lebih menyukai hal yang baru, lebih ringkas dan dengan banyak warna dan penerapan pada K13 revisi menjadi dasar peneliti dalam mengembangan media mind mapping dengan software Mindjet Mindmanager 2017.

Tahap perencanaan dilakukan setelah tahap pendefinisian dilakukan oleh peneliti. Dalam tahap perencanaan ini dilakukan sebelum dilakukannya tahapan memproduksi

\footnotetext{
${ }^{40}$ Rahayu Mugi W, I Komang Sudarma, and I Ketut Dibia, 'Enhancement Of Science Learning Outcomes Through Two Stay Two Stray Learning Model Assisted With Mind Mapping Media', Journal of Education Technology, 4.3 (2020), 218-27 <https://doi.org/10.23887/jet.v4i3.25688>.

${ }^{41}$ Wildan Navisa Barra, Insih Wilujeng, and Heru Kuswanto, 'The Effect of Inductive Learning Model Assisted Mindmap Mindjet Mindmanager towards Critical Thinking Skills of Students', Journal of Physics: Conference Series, 1233.1 (2019), p. 2 <https://doi.org/10.1088/1742-6596/1233/1/012046>.
} 
media pembelajaran yaitu perencanaan terkait media yang hendak diciptakan/dikembangkan agar sesuai dengan materi dan soal serta format yang akan digunakkan. Media pembelajaran yang dikembangkan peneliti memuat materi akuntansi dasar semester genap yaitu mulai dari materi transaksi bisnis perusahaan jasa, dagang dan manufaktur, materi jurnal, konsep debet dan kredit, saldo normal, sistematika pencatatan dan bentuk jurnal, materi buku besar, materi jurnal penyesuaian, dan yang terakhir materi neraca lajur hingga jurnal pembalik yang sesuai dengan kurikulum 2013 revisi. Pada tahapan ini peneliti membuat desain media mind mapping terlebih dahulu dan pengumpulan konten yang digunakkan dalam media agar tampilannya semakin menarik. Media yang hendak dibuat oleh peneliti dengan bantuan software Mindjet Mindmanager 2017 berisi kata kunci terkait materi dan soal akuntansi dasar semester genap yang telah terdapat catatan mengenai penjelasan dari setiap kata kunci dan dihubungkan (hyperlink) dengan software lain yaitu Microsoft word, Microsoft powerpoint ataupun gambar agar memudahkan siswa untuk memahami penjelasan dari kata kunci tersebut.

Tahap pengembangan bertujuan untuk menindaklanjuti dari tahap perencanaan yaitu menciptakan media pembelajaran berupa mind mapping. Media pembelajaran yang diciptakan adalah mind mapping dengan software mindjet manager 2017 yang disimpan dalam bentuk format (.html) agar hyperlink dapat diakses sedangkan format jpeg. diperuntugkan untuk yang mengakses media pada handphone. Media pembelajaran yang selesai diciptakan kemudian ditelaah dan divalidasi oleh para ahli baik dari ahli media maupun materi untuk memperoleh masukan maupun koreksi sebagai bahan revisi hingga media pembelajaran mendapatakan kriteria layak untuk dapat diujikan ke siswa kelas $\mathrm{X}$ AKL SMK Ketintang Surabaya sebagai sampel penelitian. Hasil dari telaah ahli materi mendapatkan saran untuk dalam beberapa istilah dilengkapi dengan pengertiannya agar siswa mudah untuk memahami materi. Ahli media memberikan saran untuk warna diubah menjadi mejikuhibiu dengan warna tulisan yang disesuaikan dengan warna background agar tetap jelas untuk dibaca dan untuk setiap backgorund pada mind mapping sebaiknya lebih transparan dan gambar pada background cukup berada dipinggir agar siswa dapat fokus dengan mind mapping yang sedang ditampilkan. Berdasarkan saran dari para ahli kemudian dilakukan perbaikan pada media mind mapping.

Validasi dilakukan setelah adanya revisi dari telaah para ahli. Hasil dari validasi dan hasil uji coba pada siswa kemudian diolah secara deskriptif kuantitatif untuk melihat kelayakan media mind mapping. Media mind mapping dinyatakan layak/sangat layak dengan presentase $\geq 61$ yang berasal dari seluruh aspek dalam media tersebut dan dinyatakan layak atau sangat layak yang didasarkan pada percobaan uji kepada siswa jika presentasenya $\geq 61 \%$. 
Berikut adalah hasil validasi oleh ahli materi dan validasi ahli media:

Tabel 5. Hasil validasi oleh ahli materi

\begin{tabular}{clcc}
\hline No. & Aspek penilaian & presentase & kriteria \\
\hline 1. & Kualitas isi dan tujuan & $82 \%$ & $\begin{array}{c}\text { Sangat } \\
\text { layak }\end{array}$ \\
\hline 2. & Kualitas instruksional & $80 \%$ & Layak \\
\hline 3. & Kualitas teknis & $75 \%$ & Layak \\
\hline & Rata-rata keseluruhan & $79 \%$ & Layak \\
\hline
\end{tabular}

Sumber: dioalah peneliti (2021)

Berdasarkan tabel 5, dari kualitas isi dan tujuan mendapatkan presentase $82 \%$ dengan kriteria "sangat layak", artinya isi dari baik dari penjelasan dari materi dan soal pada media sudah sangat lengkap dan tujuan dari materi sesuai dengan tujuan dari pembelajaran, untuk kualitas instruksional mendapatkan kriteria "layak" sebesar $80 \%$ yang menunjukkan bahwa media mind mapping dapat meningkatkan motivasi, merangsang keterampilan siswa, dan kemudahan siswa dalam memahami materi. Dan kualitas teknis sebesar $75 \%$ yang mengartikan bahwa materi pada media dalam hal keterbacaan, kualitas tampilan dan keefektifan dalam penyampaian materi mendapatkan kriteria "layak". Sedang untuk presentase rata-rata dari ketiga aspek keseluruhan yaitu 79\% dapat dinyatakan bahwasanya media mind mapping menggunakkan software Mindjet Mindmanager pada materi akuntansi dasar kelas X mendapatkan kriteria "layak".

Tabel 6. Hasil validasi oleh ahli media

\begin{tabular}{cccc}
\hline No. & Aspek penilaian & presentase & kriteria \\
\hline 1. & Kualitas isi dan tujuan & $87 \%$ & $\begin{array}{c}\text { Sangat } \\
\text { layak }\end{array}$ \\
\hline 2. & Kualitas instruksional & $90 \%$ & $\begin{array}{c}\text { Sangat } \\
\text { layak }\end{array}$ \\
\hline 3. & Kualitas teknis & $85 \%$ & $\begin{array}{c}\text { Sangat } \\
\text { layak }\end{array}$ \\
\hline & Rata-rata keseluruhan & $87 \%$ & $\begin{array}{c}\text { Sangat } \\
\text { layak }\end{array}$ \\
\hline
\end{tabular}

Sumber: dioalah peneliti (2021)

Berdasarkan pada hasil validasi ahli media, ketiga aspek penilaian diatas untuk media mind mapping dengan software Mindjet Mindmanager materi akuntasi dasar kelas $\mathrm{X}$ dengan rata-rata keseluruhan sebesar 87\% mendapatkan kriteria "sangat layak". Pada kualitas isi dan tujuan mendapatkan kriteria "sangat layak" sebesar 87\% artinya media 
sesuai dengan tujuan pada pembelajaran, sesuai dengan perkembangan teknologi dalam pendidikan, sesuai dengan materi pada akuntansi dasar, pemilihan kalimat dan tata letak media yang telah tepat. Kualitas Instruksional dengan presentase 90\% mendapatkan kriteria "sangat layak"yang dapat diartikan bahwa media mind mapping memberikan kesempatan belajar maupun bantuan belajar dalam memahami materi, mendorong siswa untuk belajar dan media mind mapping sangat fleksibel karena dapat digunakkan kapanpun dan dimanapun. Pada kualitas teknis mendapatkan kriteria "sangat layak" sebesar $85 \%$ karena media yang sangat jelas untuk dibaca ditambah dengan cara penggunaan media yang mudah dipahami dan kualitas pada tampilan mind mapping yang sudah baik.

Hasil validasi para ahli baik dari ahli materi dan ahli media tersebut menunjukkan bahwa media mind mapping yang telah dibuat oleh peneliti layak untuk digunakkan dalam proses pembelajaran mata pelajaran akuntansi dasar. Selesai validasi para ahli akhirnya menghasilkan sebuah produk berupa media mind mapping yang memiliki dua format yaitu html. dan jpeg. yang siap diujikan Media tersebut kemudian diujikan kepada 20 siswa SMK kelas X AKL dari SMK ketintang Surabaya yang merupakan sampel uji coba pada produk untuk melihat bagaimana respon dari siswa dan terkait media mind mapping.

Berikut adalah data hasil angket respon siswa terhadap media mind mapping dengan software Mindjet Mindmanager:

Tabel 7. Hasil angket respon siswa

\begin{tabular}{clcc}
\hline No. & Aspek penilaian & presentase & kriteria \\
\hline 1. & Kualitas instruksional & $95 \%$ & Sangat baik \\
\hline 2. & Kualitas teknis & $95 \%$ & Sangat baik \\
\hline & Rata-rata keseluruhan & $95 \%$ & Sangat baik \\
\hline
\end{tabular}

Sumber: dioalah peneliti (2021)

Berdasarkan pada tabel tersebut, kualitas instruksional dengan presentase 95\% mendapatkan kriteria "sangat baik" dalam hal informasi pada media yang mudah dipahami dan memotivasi siswa untuk belajar. Jika untuk kualitas teknis mendapatkan kriteria "sangat baik" sebesar 95\% karena bahasa pada media yang mudah dipahami, gambar mind mapping yang jelas, tulisan pada media yang mudah dibaca, background, warna dan huruf yang digunakkan pada media menarik siswa. Kedua aspek penilaian pada media dengan rata-rata keseluruhan 95\% mendapatkan kriteria"sangat baik" dan dapat diketahui bahwa media mind mapping yang telah dibuat peneliti memperoleh respon sangat baik pada siswa baik dari kualitas instruksional dengan presentase 95\% maupun kualias teknis dengan presentasenya $95 \%$ untuk digunakkan dalam proses pembelajaran materi akuntansi dasar pada siswa SMK kelas X AKL. 


\section{SIMPULAN}

Berdasarkan pada hasil penelitian yang telah dijelaskan diatas dapat disimpulkan bahwa 1) Model penelitian pengembangan yang digunakkan dalam pembuatan media model model 4-D Thiagarajan dengan empat tahapan yaitu yang pertama tahapan pendefinisian, kedua tahapan perencanaan, ketiga tahapan pengembangan dan terakhir tahapan penyebaran. 2) Media pembelajaran mind mapping dengan software Mindjet mindmanager 2017 materi akuntansi dasar kelas X AKL yang diciptakan oleh peneliti layak untuk digunakkan dalam proses pembelajaran. 3) Hasil dari respon siswa mengenai media mind mapping menggunakkan software Mindjet mindmanager materi akuntansi dasar kelas X AKL mendapatkan kriteria sangat baik untuk digunakkan dalam pembelajaran akuntansi dasar.

\section{DAFTAR PUSTAKA}

Aghni, Rizqi Ilyasa, 'Fungsi Dan Jenis Media Pembelajaran Dalam Pembelajaran Akuntansi', Jurnal Pendidikan Akuntansi Indonesia, 16.1 (2018), 98-107 <https://doi.org/10.21831/jpai.v16i1.20173>

Ahmad, Wan Noor Hazlina Wan Jusoh Suraya, 'IMindMap as An Innovative Tool in Teaching and Learning Accounting : An Exploratory Study', Emerald Insight, 13.1 (2016), 1-13 <https://doi.org/http://dx.doi.org/10.1108/ITSE-05-2015-0012>

Aunurrahman, Belajar Dan Pembelajaran, edisi 1 (Bandung: Alfabeta, 2014)

Bagaskara, I Made Yuda, Dewa Nyoman Sudana, and Kadek Yudiana, 'The Positive Impact of SFE Learning Model Assisted with Mind Mapping Media Toward Students' Knowledge Competence in Science', Journal of Education Technology, 4.3 (2020), 317-24 <https://doi.org/10.23887/jet.v4i3.27098>

Barra, Wildan Navisa, Insih Wilujeng, and Heru Kuswanto, 'The Effect of Inductive Learning Model Assisted Mindmap Mindjet Mindmanager towards Critical Thinking Skills of Students', Journal of Physics: Conference Series, 1233.1 (2019) <https://doi.org/10.1088/1742-6596/1233/1/012046>

Fajrina, Rani Nur Arifah, Supriyono Koes Handayanto, and Arif Hidayat, 'Deskripsi Penguasaan Konsep Siswa Terhadap Materi Fluida Statis Di Tana Paser Kalimantan Timur Kelas XI Tahun Ajaran 2016/2017', Pros.Seminar Pend.IPA Pascarjana UM, 1 (2016), 416-22

Fitriana, Eka, 'Pengembangan Media E-Modul Berbasis Aplikasi Android Materi Persamaan Dasar Akuntansi Mata Pelajaran Akuntansi Dasar Kelas X Akuntansi 
Di SMK PGRI 1 Tulungagung', Jurnal Mahasiswa Teknologi Pendidikan, 9.2 (2018)

Gunawan, Hendri, 'Pengembangan E-Modul Akuntansi Akuntansi Kompetensi Dasar Mencatat Transaksi Dalam Persamaan Dasar Akuntansi Di Sekolah Menengah

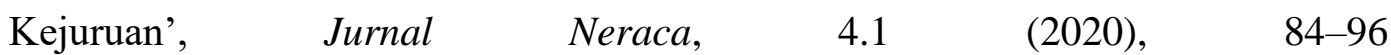
<https://doi.org/10.31851/neraca.v4i1.4311>

Indonesia, Republik, 'Peraturan Pemerintah Republik Indonesia Nomor 74 Tahun 2008 Tentang Guru', Lembaran Negara RI Tahun 2008, 2008, pasal 1 ayat 221 $<$ https://www.bertelsmann-

stiftung.de/fileadmin/files/BSt/Publikationen/GrauePublikationen/MT_Globalizati on_Report_2018.pdf\%0Ahttp://eprints.Ise.ac.uk/43447/1/India_globalisation, society and inequalities(1sero).pdf\%0Ahttps://www.quora.com/What-is-the>

—, Permendikbud Nomor 22 Tahun 2016 (Indonesia, 2016)

_- 'SE No. 4 Tahun 2020 Tentang Pelaksanaan Kebijakan Pendidikan Dalam Masa Darurat Penyebaran CoronaVirus Disease (COVID 19)', 2020, 1-3

Kalyanasundaram, Madhanraj, Shrein Billy Abraham, Divija Ramachandran, Venkatachalam Jayaseelan, Joy Bazroy, Zile Singh, and others, 'Effectiveness of Mind Mapping Technique in Information Retrieval among Medical College Students in Puducherry-A Pilot Study', Indian Journal of Community Medicine, 42.1 (2017), 19-23 <https://doi.org/10.4103/0970-0218.199793>

Khabibah, Nur, and Agus Wahyudin, 'Pengaruh Pemahaman Analisi Transaksi, Persamaan Dasr Akuntansi Dan Konsep Debit Kredit Terhadap Hasil Belajar Jurnal Penyesuaian Dengan Kemampuan Berpikir Deduktif Sebagai Variabel Moderating', Economic Education Analysis Journal, 9.1 (2020), 182-99 <https://doi.org/10.15294/eeaj.v9i1.37248>

Kholid, Hamas Nur, and Amanita Novi Yushita, 'Pengembangan Media Pembelajaran Akuntansi “Accountainment” Pada Kompentensi Dasar Menyiapkan Jurnal Umum Untuk Meningkatkan Motivasi', Kajian Pendidikan Akuntansi Indonesia, 6.8 (2017), 1-25

Muhlisin, Ahmad, 'Reading, Mind Mapping, and Sharing(RMS): Innovation of New Learning Model on Science Lecture to Improve Understanding Concepts', Journal for the Education of Gifted Young Scientists, 7.2 (2019), 323-40 <https://doi.org/10.17478/jegys.570501>

Nurhasanah, Siti, and A. Sobandi, 'Minat Belajar Sebagai Determinan Hasil Belajar Siswa', Jurnal Pendidikan Manajemen Perkantoran, 1.1 (2016), 128-35 <https://doi.org/10.17509/jpm.v1i1.3264> 
Oktaviana, Argelina Novi, and Guntur Trimulyono, 'Kelayakan Teoritis Media Video Mind Mapping Untuk Melatih Kemampuan Berpikir Kreatif Peserta Didik Kelas X Pada Materi Fungi', BioEdu Berkala Ilmiah Pendidikan Biologi, 7.2 (2018), 18793

Prihastuti, Asepma Hygi, and Suci Ramadhani, 'Penerapan Metode Pembelajaran Mind Mapping Dan Problem Based Learning Pada Mata Kuliah Akuntansi Keuangan Lanjutan', Eklektik: Jurnal Pendidikan Ekonomi Dan Kewirausahaan, 2.2 (2019), 215-31 <https://doi.org/10.24014/ekl.v2i2.8632>

Putri Ningrat, Sayu, I Made Tegeh, and Made Sumantri, 'Kontribusi Gaya Belajar Dan Motivasi Belajar Terhadap Hasil Belajar Bahasa Indonesia', Journal of Education Technology, 2.4 (2018), 145-52 <https://doi.org/10.23887/jisd.v2i3.16140>

Putri, Nurfiah Alfiani, Ajo Dian Yusandika, and Deden Makbuloh, 'Pengembangan Media Pembelajaran Berbasis Mindjet Mindmanager 2017 Pada Pokok Bahasan Usaha Dan Energi', Indonesian Journal of Science and Mathematics Education, 2.1 (2019), 55-63 <https://doi.org/10.24042/ijsme.v2i1.3972>

Republik, Indonesia, 'Peraturan Menteri Pendidikan Dan Kebudayaan Republik Indonesia Nomor 22 Tahun 2020 Tentang Rencana Strategis Kementerian Pendidikan Dan Kebudayaan Tahun 2020-2024', Lembaran Negara RI Tahun 2020, 2020

Riduwan, Skala Pengukuran Dan Variabel-Variabel Penelitian (Bandung: Alfabeta, 2016)

Sadiman, Dkk, Media Pendidikan: Pengertian, Pengembangan, Dan Pemanfaatannya (Jakarta: PT. Raja Grafindo, 2014)

Sucipto, Toto, Akuntansi Dasar Program Keahlian Akuntansi Dan Keuangan, ed. by Gafar Erickasman (Yudhistira, 2017)

Sugiyono, Metode Penelitian Kuantitatif, Kualitatif, Dan R\&D (Bandung: Alfabeta, 2017)

Susanto, Arief Davis Bagus, 'Analisis Perbandingan Hasil Belajar Siswa Pada Penerapan Pembelajaran Melalui Pendekatan Saintifik Dengan Dan Tanpa Berbantuan Mind Mapping Pada Mata Pelajaran Dasar - Dasar Perbankan Kelas X Akuntansi Di SMK Negeri 2 Buduran', Jurnal Pendidikan Akuntansi (JPAK), 6.3 (2018), 226-29

Trianto, Mendesain Model Pembelajaran Inovatif Progresif Dan Kontekstual (Jakarta: Kencana Prenada Media Group, 2015)

Umi, Choiriyati, 'Upaya Meningkatkan Kemampuan Siswa Dalam Penguasaan Materi Pembelajaran Persamaan Dasar Akuntansi Dengan Metode Optimalisasi Pembelajaran Berjenjang Pada Siswa Kelas XII IPS 1 SMAN 1 Pringgasela 
Semester Ganjil T.P 2017-2018', Journal Ilmiah Rinjani_Universitas Gunung Rinjani, 6.2 (2018), 189-200

W, Rahayu Mugi, I Komang Sudarma, and I Ketut Dibia, 'Enhancement Of Science Learning Outcomes Through Two Stay Two Stray Learning Model Assisted With Mind Mapping Media', Journal of Education Technology, 4.3 (2020), 218-27 <https://doi.org/10.23887/jet.v4i3.25688>

Wardani, Randi Kusuma, Amiruddin Kasim, and Amran Rede, 'Pengaruh Penggunaan Mind Manager Terhadap Motivasi Dan Hasil Belajar Siswa Kelas VII SMPN 3 Palu Pada Mata Pelajaran Biologi’, E-Jip Biol, 5.1 (2017), 26-34

Wibawanto, Wandah, Desain Dan Pemrograman Multimedia Pembelajaran Interaktif, ed. by Dhega Febiharsa, 1st edn (Jember: Penerbit Cerdas Ulet Kreatif, 2017) $<$ https://play.google.com/books/reader?id=9pULDgAAQBAJ\&hl=id\&lr=\&prints ec $=$ frontcover\&pg=GBS.PR2> 